\title{
FUTURE-SE: REFLEXÕES A PARTIR DE UMA IDEOLOGIA DA COMPETÊNCIA E AUTORITARISMO
}

\author{
Future-se: reflections from an ideology of competence and authoritarianism
}

\author{
Greice Martins Gomes'
}

\begin{abstract}
Resumo
O tema central deste artigo volta-se para processos de formulação de políticas educacionais a partir da relação entre ação governamental e premissas empresariais. É neste sentido que tomamos como elemento disparador, para tal debate, o Future-se, programa de contrarreforma universitária lançado pelo Ministério da Educação (MEC) em julho de 2019. Para fins de desenvolvimento teórico-argumentativo articulamos dois conceitos centrais: ideologia da competência e autoritarismo. De modo geral este trabalho parte da problematização quanto a determinado engendramento em curso que diz respeito a um processo de mutação no ensino superior, bem como do significado da universidade pública. Neste cenário a educação tende a ser vista não mais como um direito, mas como um serviço e a universidade não mais reconhecida como uma instituição social mas como uma Organização ${ }^{2}$ pensada e conduzida a partir de premissas administrativas voltadas para o mercado.
\end{abstract}

Palavras-chave: Ideologia da competência; Autoritarismo; Future-se.

Abstract: The central theme of this paper focuses on educational policymaking processes based on the relationship between governmental action and business premises. It is in this sense that we take as triggering element, for such debate, the Future-se, university counterreform program launched by the Ministry of Education (MEC) in July 2019. For the purposes of theoretical-argumentative development we articulate two core concepts: ideology of competence and authoritarianism. In general, this work starts from the problematization regarding a certain ongoing engineering that concerns a process of mutation in higher education, as well as the meaning of the public university. In this scenario, education tends to be seen no longer as a right, but as a service and the university no longer recognized as a social institution but as an Organization conceived and conducted based on market-oriented administrative premises.

Keywords: Ideology of competence; Authoritarianism; Future-se.

\footnotetext{
1 Doutoranda no Programa no Pós-Graduação em Administração (UFRGS), Mestre em Sociologia (UFPel) com sanduíche pela Universidade de Coimbra (PT), Especialista em Psicologia Organizacional, Bacharel em Administração. E-mail: greice.martins.gomes@gmail.com

2 Faz pertinente esclarecer, aqui, que a expressão Organização, com sua inicial em maiúscula, a diferencia de outras formas organizativas. Na descrição proposta pela autora Organização se relaciona a ideia de empresa. Tal expressão é de inspiração francfurtiana, feita por Michel Freitag em Le naufrage de l'université. Paris: Editions de la Découverte, 1996.
} 
Future-se: reflexões a partir de uma ideologia da competência e autoritarismo | Greice Martins Gomes

\section{Introdução}

O presente trabalho parte da problematização quanto a um processo em curso que diz respeito a uma mutação no ensino superior, bem como do significado da universidade pública. De modo que, tendo como tema geral a formulação de politicas educacionais a partir da relação entre ação governamental e premissas empresariais, tomamos como elemento disparador para tal debate o programa Future-se. Este último, enquanto projeto de contrarreforma universitária, trata-se de uma proposta governamental lançada no primeiro semestre de 2019 que prevê e.g., a ampliação de investimentos privados nas universidades públicas, o estímulo à competição entre departamentos, a negociação de "naming rights"(direitos de nome, tradução nossa) para prédios e instalações como ocorre, por exemplo, em estádios de futebol, bem como a permissão de contratos com organizações sociais para cessão de uso, concessão, comodato e fundo de investimento imobiliário das universidades (MEC, 2019). Ou, ainda, como discorreu o secretário de Educação Superior do MEC na apresentação do projeto em 17 de julho de 2019 "não é dinheiro que está faltando nas universidades federais, mas sim gestão" (ADUSP, 2019). Claramente, embutido em tal afirmação, estão determinadas premissas. Possivelmente a mais relevante para nossa discussão remete-nos a uma linha de pensamento baseada em modelos padronizados de conduta e postura, que à medida que enaltecidos por um presumido aumento da 'eficiência' obscurecem seu significado político. Este último, amparado em um ideal neoliberal, entende a vida social a partir em uma racionalidade instrumental, como discutiremos.

Para fins de desenvolvimento deste artigo tomaremos como referencial teórico o conceito de ideologia da competência de Marilena Chauí (2014, 2015, 2016, 2017). Tal conceito trata-se de um imaginário social estruturado a partir de três grandes inversões ideológicas: substitui a lógica da produção pela da circulação (donde a ideia de que, nas universidades, a 
Future-se: reflexões a partir de uma ideologia da competência e autoritarismo | Greice Martins Gomes

avaliação não deve ser feita pela qualidade do trabalho mas pela quantidade de circulação do que é produzido); substitui a lógica do trabalho pela da comunicação (donde a ideia de que dispositivos técnicos/tecnológicos são recursos mais importantes do que professores bem formados e bem pagos) e substitui a lógica da luta de classes pela da relação dos indivíduos com o consumo (CHAUí, 2014). Apesar de nos associarmos a noção de que ações governamentais como o Future-se se ligam à ideia de uma mudança maior gerida dentro de uma escala global e relacionada a uma mudança mundial na forma atual assumida pelo capitalismo, ou seja, o neoliberalismo entendemos que, no Brasil, este tipo de mutação não pode ser desatrelada de uma propriedade a nós atinente e que indubitavelmente acrescenta característica (outras) às transformações que vivenciamos. Assim, mesmo que uma ideologia da competência tenha sua origem e disseminação inicial ocorrida internacionalmente, ela acaba sendo adaptada aos diferentes ditames dos capitalismos por onde se integra e, evidentemente, isso Brasil não é diferente. A base de nosso argumento volta-se então ao fato de que, no caso brasileiro, um fator agravante (e também particular) ao modelo neoliberal que aqui se instalou está, justamente, ligado à nossa matriz social autoritária. Motivo pelo qual optamos por trazer a este debate a noção de autoritarismo ao que tomaremos como referencial a obra 'Sobre o Autoritarismo Brasileiro' (2019) de Lilia Schwarcz. Cientes de que faz parte do discurso autoritário silenciar sobre sua própria existência, parece-nos oportuno trazê-lo a esta discussão a fim de alargarmos nossa reflexão quanto a projetos governamentais que se nutrem, manifestadamente, de axiomas empresariais para pensar politicas sociais.

Assim, na primeira seção deste material articularemos uma breve discussão sobre o projeto Future-se voltada, em especial, à questão da autonomia universitária. Esta última trata-se da garantia que, independente de governos e Estados, mercado ou religião, o conhecimento terá liberdade para ser produzido. O Future-se coloca em risco a autonomia universitária de uma forma singular inclusive em relação ao que já vivenciamos em um 
Future-se: reflexões a partir de uma ideologia da competência e autoritarismo | Greice Martins Gomes

período ditatorial. $\mathrm{Na}$ atualidade, a educação à medida que entendida enquanto um produto faz com que a universidade se veja submetida a declinar de seus ideais formadores, de crítica e reflexão social, e passe a ser pensada a partir de uma ideologia da competência, como discutiremos na segunda seção deste artigo.

A ideia fundante de uma ideologia da competência está na forma de funcionamento da Organização e das chamadas leis do mercado (CHAUÍ, 2014). A Organização pressupõe uma racionalidade em que os meios de ação inutilizam qualquer reflexão acerca da racionalidade dos fins da ação e, não obstante, tomar universidade - enquanto Organização - significa considerá-la a partir da ideia e da prática da administração. Dentro de uma forma conservadora de se pensar a administração, ou seja, enquanto conjunto de prescrições, normas e princípios que são idênticos à todas as formas organizativas, tratar-se-á, exatamente, da mesma coisa administrar uma fábrica, uma loja, um supermercado, uma igreja, uma creche, um hospital e, claro: uma universidade. É este modo de pensar a administração que transforma uma instituição social em uma Organização, isto é, em uma prática administrativa apenas. Ao que nos questionamos: o que torna possivel migrarmos da ideia de universidade enquanto instituição social para a sua definição como Organização? Um caminho para esta reflexão perpassa a própria noção de neoliberalismo e suas formas de estruturação contemporâneas. Dentro de uma concepção neoliberal a educação passa a ser um negócio, um produto, muito mais do que um meio de aprimoramento individual, inclusão social ou mesmo desenvolvimento nacional.

$\mathrm{Na}$ terceira seção, articulamos elementos que sobrecarregam tal cenário e que dizem respeito a dificuldades específicas e presentes em nossa sociedade. Fruto de construções históricas passadas, o autoritarismo engendrado através de séculos de escravidão, mandonismo e patriarcalismo (SCHWARCZ, 2019) - eclode nos dias atuais através de construções tais como: o esvaziamento sobre nossa ideia de alteridade bem a o que vem a ser um direito; a dificuldade de lidar com a igualdade que conduz a se pensar investimentos estatais, como uma educação pública, democrática e 
Future-se: reflexões a partir de uma ideologia da competência e autoritarismo | Greice Martins Gomes

universal, não enquanto forma de desenvolvimento social, mas como um dispêndio de recursos do Estado; e o desprezo a formas de pensamento crítico e reflexivo que, por sua vez, leva ao desprestigio e à deslegitimidade da própria instituição universidade tal como a conhecemos.

\section{Future-se e autonomia universitária, incompatibilidade de princípios?}

O Future-se encontra-se estruturado a partir de três eixos: gestão, governança e empreendedorismo; pesquisa e inovação; e internacionalização (MEC, 2019). No o material divulgado pelo Ministério da Educação, o primeiro eixo traz propostas tais como limite de despesas com pessoal das universidades e a possibilidade de se criar ranking de instituições federais de ensino superior (IFES) com base na melhor eficiência de gastos, premiando-se as melhores práticas e criação de códigos de autorregulação com aprimoramento da governança e da auditoria externa, a exemplo do IBGC. Esta sigla faz referência ao Instituto Brasileiro de Governança Corporativa, Organização Social, que tem entre seus mantenedores os bancos Bradesco, Itaú e Santander bem como a Bolsa de valores do Estado de São Paulo (ADUSP, 2019).

Pensado a partir de tais proposições e mesmo que ainda esteja em trâmite no momento em que escrevemos este material - ou seja, tal projeto de contrarreforma universitária ainda não foi apresentado à Câmara ou ao Senado, nem mesmo aprovado (ou negado) pelo Congresso - o Future-se ${ }^{3}$ já vem provocando inúmeros debates desde seu lançamento. No que diz respeito à comunidade acadêmica, a desconfiança converge sobre quais seriam as (reais) intenções do Ministério da Educação com tal proposta. Para fins desta discussão nos concentraremos de forma conjectural nos processos ligados ao modelo de gestão/governança relativos ao programa. Para tanto adotaremos como base de nosso argumento aquilo que vem a ser um dos

\footnotetext{
3 Faz-se relevante comentar que nosso objetivo, no presente trabalho, não é adentrar os pormenores sobre tal programa visto a larga produção que já se encontra disponivel neste sentido. Este texto procura complementar as várias manifestações que têm surgido desde então.
} 
Future-se: reflexões a partir de uma ideologia da competência e autoritarismo | Greice Martins Gomes

pilares do ensino superior nas sociedades modernas, ou seja, a autonomia universitária.

Quanto a isto é pertinente lembrarmos que desde o seu surgimento, no século XIII, na Europa, a universidade se formou com base em dois princípios balizadores: reconhecimento público de sua legitimidade e atribuições, bem como diferenciação em virtude de sua autonomia frente a outras instituições (CHAUI, 2015). A autonomia das universidades é a garantia que independente de governos e estados, mercado ou religião, o conhecimento gozará de liberdade para ser produzido. No caso do Brasil, a autonomia universitária foi formalmente garantida pela Constituição de 1988 em que the foi assegurada autonomia financeira, administrativa e liberdade de pensamento. Como coloca Chauí (2015), a legitimidade da universidade nos tempos modernos se fundou na ideia de autonomia, em especial, uma autonomia do saber e, portanto, na perspectiva de um conhecimento guiado por necessidades imanentes ao próprio saber. Segundo a autora, a autonomia universitária possui um sentido sócio-político, uma vez que pode ser vista como a marca peculiar de uma instituição que possui na sociedade seu princípio de regulação e de ação.

O Future-se coloca em risco a autonomia universitária de maneiras variadas, mas, possivelmente, sua forma mais categórica se mostre através de sua natureza propositiva de entender a educação enquanto um 'produto' e não como um 'bem público', este último, voltado para o desenvolvimento da capacidade reflexiva e criativa quanto a produção do conhecimento. $\mathrm{Ou}$ como colocou Arnaldo Barbosa de Lima Júnior, secretário de Educação Superior do MEC, na apresentação pública do programa, "A gente quer fazer com que a educação brasileira seja um produto tipo exportação" (ADUSP, 2019, grifos nossos). A base para que isto se torne realidade está na ancorada no incentivo a uma entrada ostensiva de recursos privados nas federais, o que, em larga medida, direcionaria uma subordinação do conhecimento aos interesses do capital. Mas como seria factivel pensar tal relação? Uma resposta para essa questão perpassa pela consciência de que, falando de empresas privadas, ou seja, com fins lucrativos, é evidente 
Future-se: reflexões a partir de uma ideologia da competência e autoritarismo | Greice Martins Gomes

ponderar que acontece financiamento privado onde há expectativa de lucro. As pesquisas nas universidades, nesse sentido, deixariam de ser de toda a população, fugindo, portanto, de sua perspectiva democrática (enquanto sentido lato da palavra (democracia') e passariam a ser norteadas pelo mercado, ou seja, por empresas que melhor pagarem pelas investigações.

Ainda sobre a captação de recursos, Fundos imobiliários e patrimoniais (que permitirão tais "doações" de empresas) poderão ser constituídos para a venda ou concessão de imóveis e terrenos que hoje pertencem às instituições universitárias. Ao que o secretário de Educação Superior, Arnaldo Lima, afirmou que terrenos das Universidades poderiam, como exemplifica, ser transformados em "shoppings" como forma de alavancar a obtenção de recursos junto ao mercado (NEXO, 2019); A pasta também defende a comercialização de "naming rights" que permite à empresas e patrocinadores darem seus nomes de empresas à prédios ou mesmo aos campis das instituições, tal recurso, hoje, é usado em estádios de futebol como o do Palmeiras, rebatizado de Allianz Parque.

A coordenadora do programa de pós-graduação em educação da UFPA (Universidade Federal do Pará) e pesquisadora do CNPq (Conselho Nacional de Desenvolvimento Científico e Tecnológico), Vera Jacob, que estuda o tema do financiamento privado na educação superior no Brasil desenvolveu sua tese de doutorado a este respeito. Conforme relata, os resultados de seus estudos apontaram que o impacto que pesquisas fruto de captação financeira no mercado trazem a universidade é insipiente. Isto ocorre, em parte, porque o 'produto final' passa a ser da empresa financiadora, restando às instituições apenas ganhos secundários que pouco ou nada influenciam em orçamento final das instituições, como esclarece:

Nos projetos que investiguei na minha tese de doutorado, num dos contratos que analisei de parceria públicoprivada, a empresa não cedia nada de patente para a universidade. O que eu consegui identificar de retorno? O laboratório teve os equipamentos modernizados, alguns estudantes conseguiram bolsas, mas a empresa se beneficiou muito mais, porque não tinha nenhuma responsabilidade com contratação de pessoal, que é a 
Future-se: reflexões a partir de uma ideologia da competência e autoritarismo | Greice Martins Gomes

parte mais cara da pesquisa. A estrutura é da universidade, a energia elétrica é paga pela universidade. Efetivamente, isso não tem impacto. $O$ impacto no orçamento da universidade é quase zero. (NEXO, 2019).

Ademais, de acordo com o que coloca Chauí (2016), a "flexibilização" é uma consequência da quebra dos princípios de autonomia, sendo que flexibilizar significa na realidade: 1) eliminar o regime único de trabalho, o concurso público e a dedicação exclusiva, substituindo-os por 'contratos flexiveis', isto é, temporários e precários. E como isto se mostra no programa future-se? Através, por exemplo, do conteúdo presente em tal projeto de lei que estabelece às universidades federais um compromisso de redução de despesa com pessoal. Segundo consta na segunda versão deste documento, a diminuição dos gastos constitui 'indicador obrigatório’ para todo o contrato que passar a ser firmado com as universidades (MEC, 2019). Abre-se, com isto, a possibilidade para a mudança de regime jurídico de contratação (desestimulando e.g., a dedicação exclusiva que se constitui como relevante fator para produção científica), bem como abre possibilidade para novas formas de contratação precárias; 2) simplificar processos de compras (as licitações) e as prestações de contas para proteção das chamadas "outras fontes de financiamento", sobre tudo, para que se proteja aquilo que não se pretende ver controlado ou mesmo exposto. Isto revela-se no Future-se através, por exemplo, de sua proposta de alteração do artigo da LDB (Lei de Diretrizes e Bases da Educação) para que o título de notório saber possa ser reconhecido por uma universidade com curso de pós-graduação (não necessariamente de doutorado) suprimindo-se a exigência de titulação/formação acadêmica; 3) adaptar os currículos de graduação e pósgraduação às necessidades as diferentes regiões do país (ou seja, as demandas empresariais locais). Articulação não formalizada no projeto, mas presente nas palavras do Ministro da Educação ao afirmar que universidades do Nordeste deveriam deixar de ensinar disciplinas como filosofia e sociologia, para focar no ensino de agronomia ${ }^{4}$ e, por fim, 4)

\footnotetext{
4 Declaração proferida durante transmissão ao vivo nas redes sociais em setembro de 2019. Disponivel em <https://revistaforum.com.br/politica/ministro-da-educacao-acha-que-universidadesdo-nordeste-nao-deveriam-ensinar-sociologia/> Acesso em 07 de jan de 2020.
} 
Future-se: reflexões a partir de uma ideologia da competência e autoritarismo | Greice Martins Gomes

separar a docência da pesquisa para que desta forma facilite-se o deslocamento desta última para centros autônomos, nomeadamente voltados ao atendimento das demandas dos mercados e de financiadores que melhores pagarem por determinada pesquisa.

O discurso modernizador por trás do Future-se (presente inclusive na forma de nomear tal projeto ao que mete a ideia de futuro, de modernidade, de novidade, porvir) trata-se, na realidade, de 'mais do mesmo'. Não é de hoje que governos, empresas, elites predatórias, se valem de nosso vício autoritário para se apropriar do que lhes surge como pertinente, em dado momento sociohistórico, a fim de promover reformas educacionais em prol do mercado. Observemos, neste sentido, que a ditadura militar tinha seus princípios voltados para um modelo de crescimento nacional em que educação e treinamento se igualavam. A educação superior era pensada enquanto modo de formação de mão de obra voltada para o mercado de trabalho e não de desenvolvimento de consciências e, evidentemente, muito menos de pensamento crítico. Ademais, foi durante o período ditadura militar no Brasil (1964-1985) que se promoveu uma ampliação da iniciativa privada no ensino superior caracterizada, naquele momento, por uma prática de um ensino tradicional, funcional e despreocupada com a qualificação do corpo docente. Neste momento de nossa história observou-se uma expressiva diminuição de investimentos por parte do Estado nas universidades públicas que, conforme Durham (2003), deu-se na mesma proporção em que se observava a ascensão do regime antidemocrático da ditadura militar onde as universidades federais e o movimento estudantil foram silenciados, mantidos sob forte vigilância e rotulados como agentes de subversão. Com o fim da ditadura no Brasil e a consolidação de um novo modelo econômico, produto da ascensão e hegemonia do neoliberalismo, o autoritarismo ganha suporte através de uma ideologia da competência. $\mathrm{O}$ saber, outrora instrumentalizador e funcional da ditadura, efetiva-se agora 
Future-se: reflexões a partir de uma ideologia da competência e autoritarismo | Greice Martins Gomes

como mercadoria e a universidade é 'novamente'5 questionada quanto à sua autonomia, como discutimos. De modo que, o que assistimos hoje é, em larga medida, fruto do entrelaçamento de manifestações que perpassam um intricado campo, que vai desde as atuais (e lamentáveis) apologias a um período obscuro de ditadura militar até a exacerbação de um ideal neoliberal. Neste contexto, o que se observa é que a universidade acaba sendo compelida, cada vez mais, a declinar de ideais formadores de crítica e reflexão social para ser encarada como uma Organização. Tal metamorfose estrutural reflete a passagem de uma noção de Instituição (Social) à de Organização, o que significa, antes de mais nada, pensar a universidade a partir de uma ideologia da competência (CHAUI, 2015).

\section{Ideologia da competência, um modelo organizativo-administrativo de ver o mundo}

A ideologia da competência surge como uma forma de se justificar determinados engendramentos sociais, dentro de uma dada racionalidade, bem como dissimular formas contemporâneas de exploração e dominação atreladas a concepções neoliberais. Entretanto isso não irrompe do nada, ou seja, existe um discurso que sustenta tal ideologia: o discurso competente. Neste a linguagem sofre um processo de restrição, isto é, o modelo discursivo é baseado na seguinte proposição: não é qualquer um que pode dizer qualquer coisa em qualquer lugar e em qualquer circunstância. O discurso competente "é aquele que pode ser proferido, ouvido e aceito como verdadeiro" (CHAUI, 2014, p. 7) ao passo que se confunde com a linguagem institucionalmente permitida ou autorizada, uma vez que nele há uma demarcação definida quanto a quem podem ser os interlocutores (autorizados a falar), o tempo, o lugar, a forma e o conteúdo.

\footnotetext{
5 Colocamos em destaque a palavra 'novamente', pois durante a ditadura militar uma das bandeiras de luta das universidades públicas foi justamente pela autonomia, ou seja, para que as decisões pudessem ser tomadas pelas próprias universidades, a partir de seus órgãos de colegiado, sendo uma das principais reivindicações naquele periodo era a possibilidade de eleição direta de seus reitores Importante conquista que é colocada em risco atualmente a partir da Medida Provisória (MP) 914/2019, editada no dia 24 de janeiro de 2020. De acordo com o texto, serão impostas novas regras para a escolha dos reitores das instituições federais de ensino do país. Ela torna as consultas internas obrigatórias para a definição de uma lista tríplice a ser apresentada ao presidente da República, que escolherá, então, uma das opções.
} 
Future-se: reflexões a partir de uma ideologia da competência e autoritarismo | Greice Martins Gomes

Sinteticamente, ideologia é um corpo explicativo e também prático (dita normas, regras, formalidades) de caráter regulador, prescritivo e normativo que possui uma função, qual seja: dar, aos membros de uma sociedade dividida em classes uma explicação racional para as diferenças sociais, politicas e culturais "sem jamais atribuir tais diferenças à divisão da sociedade em classes" (CHAUI, 2014, p. 53). Logo, a função da ideologia é justamente ocultar, fazer desaparecer, maquiar a existência de uma realidade que envolve exploração econômica, dominação política e exclusão cultural. No lugar deste ocultamento, a ideologia coloca um ideário de liberdade, de igualdade, de nação, ao passo que, como já dizia Marx ${ }^{6}$, a ideologia é difusão para toda a sociedade de ideias e valores da classe dominante como se tais valores fossem universais e os únicos válidos. Refere-se, portanto, a um discurso legislador, ético e pedagógico (LEFORT, 1974) que estabelece para toda a sociedade aquilo que será considerado como bom e mau, verdadeiro e falso, justo e injusto, normal e patológico, belo e feio, aceitável e não aceitável, lícito e ilícito, assim como serve para pôr uma suposta "ordem" no mundo.

A ideologia dominante afirmava-se, em tempos passados, especialmente através de um (pré)suposto valor, benéfico e universal, de algumas instituições como a família, a igreja, a empresa, a pátria e, com isto, designava os detentores legitimos do poder e da autoridade: o pai, o padre ou pastor, o patrão, o governante (CHAUI, 2014). Já a ideologia da competência começa a ser gestada no interior do fordismo, através do que seria uma divisão entre a gerência científica e o trabalho especializado, entre a "competência dos administradores e a incompetência dos trabalhadores que devem ser controlados e dirigidos pela gerência" (ROCHA, 2014, p.8-9). Enquanto que na ideologia burguesa primordial (pré-fordista) as ideias eram produzidas e validadas a partir de determinados agentes sociais (o pai, o padre ou pastor, o patrão, o governante), agora, as ideias a partir de uma

\footnotetext{
${ }^{6}$ MARX, K. A Ideologia alemã. Porto: Edições 70, 1992. 
Future-se: reflexões a partir de uma ideologia da competência e autoritarismo | Greice Martins Gomes

ideologia da competência emanam diretamente do funcionamento da Organização e das chamadas leis do mercado (CHAUI, 2017).

Organização é aquilo que norteia uma forma de racionalidade, um modo de ver/entender o mundo, ou seja, ela "pressupõe a crença na realidade em si e para si da sociedade, de tal modo que a racionalidade dos meios de ação inutiliza automaticamente qualquer questão acerca da racionalidade dos fins da ação" (CHAUI, 2017, p. 9). Ela também se funda a partir da existência de um sistema de autoridade baseado na hierarquia em que a dominação tende a permanecer oculta ou dissimulada graças a crença em uma 'racionalidade'7 administrativa e administradora. Chauí (2014) nos coloca que organizar é administrar, e administrar é, por sua vez, instaurar racionalidades nas mais variadas formas de relações sociais para além do comércio, serviços e indústria como também para escolas, hospitais, instituições psiquiátricas, sindicatos, e o próprio Estado.

A racionalidade normalmente ligada à administração e ao "administrar" trata-se de uma racionalidade instrumental. A partir de Guerreiro Ramos (1989), podemos observar que na racionalidade instrumental - que se contrapõe à racionalidade substantiva (ou noética) - a preocupação central está justamente na coordenação entre meios e fins, com a busca da eficiência operacional. Tal racionalidade tem como orientação a consecução de objetivos técnicos ou de fins vinculados a interesses econômicos, sua prioridade está galgada no o cálculo utilitário de consequências e a maximização de resultados. Neste modelo de pensamento, há um espaço escasso e restritivo para julgamentos de valor sobre justo e injusto, individual e coletivo, egoísmo e generosidade, justiça e injustiça, ganância e humanitarismo, equidade e desigualdade, inclusão e exclusão social.

7 O conceito de racionalidade, na literatura sociológica clássica, representa o elemento mais importante do pensamento de Max Weber. 
Future-se: reflexões a partir de uma ideologia da competência e autoritarismo | Greice Martins Gomes

Logo, pensar a universidade enquanto Organização ${ }^{8}$ significa tomar a universidade a partir da ideia e da prática da administração. A ideia de administração é inseparável do modo de produção capitalista enquanto produção de equivalentes para o mercado. A universalição dos equivalentes faz com que tudo no capitalismo seja equivalente a tudo, ou seja, que cada coisa - como equivalente - possa ser considerada homogênea a qualquer outra coisa, embora, aparentemente diferente dela (CHAUI, 2015). É esta homogeneização de todas as coisas como equivalentes, desenvolve Chauí (2015), que permite o aparecimento da ideia e da prática da administração. $\mathrm{Na}$ forma conservadora de se pensar a administração, enquanto determinado conjunto de regras e princípios formais que são idênticos para todas as organizações sociais, como já comentamos, não haverá diferença entre administrar um shopping center, uma montadora de automóveis, uma ONG, um asilo, uma escola ou uma universidade. Assim, é este modo de pensar a administração que transforma uma instituição social em uma Organização.

Uma Organização difere-se de uma instituição social porque se define por uma outra prática que é a da instrumentalidade. A primeira está referida ao conjunto de meios particulares para a obtenção de um objetivo igualmente particular, não estando referida, portanto, a ações articuladas às ideias de reconhecimento e legitimidade (internos - de seus pares, nem externos - de toda a sociedade) como uma instituição social (CHAUI, 2015). $\mathrm{Na}$ Organização, a ação social está ligada a ideia de operações que são definidas a partir das ideias de eficácia e sucesso no emprego de determinados meios para alcançar um objetivo particular definido por ela. Não compete a uma Organização discutir ou questionar a sua própria existência, a sua função no interior da sociedade e da luta de classes, pois estas questões - que são fundamentais para uma instituição como as

\footnotetext{
8 Pensar a universidade enquanto uma empresa (ou como uma Organização) remete a um conteúdo amplo e fértil, contudo, por limitação de espaço e escolhas teórico-metodológicas nos concentramos, em especial, nos escritos de Marilena Chauí sobre este tópico. Para desenvolver seu arcabouço conceitual, nomeadamente o de ideologia da competência, a autora reúne e interliga uma série de fenômenos estudados por outros autores sobre diversos ângulos partindo de uma interrogação sobre a gênese e o sentido da ideologia da competência desde a regulação fordista estendendo-se até o momento neoliberal contemporâneo.
} 
Future-se: reflexões a partir de uma ideologia da competência e autoritarismo | Greice Martins Gomes

universidades - são simplesmente um dado de fato. Para Chauí (2015), a instituição social aspira pela universalidade, a Organização, por sua vez não tem, em nenhuma hipótese, essa aspiração, pois sabe que sua eficácia e o seu sucesso dependem, muito pelo contrário, da sua particularidade, ou seja, naquilo que a tornará justamente específica, exclusiva, diferenciada. Isto significa que a instituição terá toda a sociedade como seu princípio e como sua referência valorativa enquanto que a Organização terá apenas a si mesma como referência em um processo de competição com outras organizações que fixaram os mesmos objetivos particulares. Em outras palavras, uma instituição social se percebe inserida na divisão social e política, pelo contrário, a Organização pretende gerir o seu espaço e seu tempo particulares onde o seu alvo não é responder as contradições econômicas, sociais e políticas e sim vencer a competição dentro de um ambiente específico (CHAUI, 2015). Mas como foi possivel passarmos da ideia de universidade enquanto instituição social para a sua definição como Organização?

A passagem da universidade da condição de uma instituição social para a de uma Organização insere-se dentro de processo de mudança social associados as novas formas do capital que, como coloca Chauí (2016), ocorreu em duas fases sucessivas. Numa primera fase, tornou-se universidade fucional; na segunda universidade operacional. A universidade funcional estava voltada para a formação rápida de profissioais requisitados como mão de obra altamente qualificada para o mercado de trabalho. Visando tal adaptação a universidade modificou seus currículos, programas e atividades para garantir a inserção dos estudantes no mercado de trabalho, separando cada vez mais docência de pesquisa. Já, a nova universidade operacional - consolidada no final dos anos 1990 com os governos de Fernando Henrique Cardoso-, justamente por pensar a universidade enquanto uma Organização está voltada para si mesma enquanto uma estrutura de gestão, de arbitragem, de controle e mediação de contratos. De forma que, regida por contratos de gestão e mensurada a partir de indices de produtividade a universidade operacional está 
Future-se: reflexões a partir de uma ideologia da competência e autoritarismo | Greice Martins Gomes

estruturada com base na ideia de meios e fins. Ou seja, ela deixa de concentrar-e na produção do conhecimento e a formação intelectual como sendo seu bem maior para pulveriza-se em micro-processos, que tando ocupam seus docentes quanto compelem seus discentes a a exigências exteriores ao trabalho intelectual. Voltada para ela mesma e para seus processos internos, a universidade operacional não age para e pela sociedade e sim opera em termos funcionais, administrativos.

A noção de uma ideologia da competência está amparada, basilarmente, sob uma ótica neoliberal. Sendo que "o que chamamos de neoliberalismo nasceu de um grupo de economistas, cientistas, políticos e filósofos, entre os quais Popper e Lippman, que, em 1947, se reuniu em Mont Saint Pèlerin, na Suíça, à volta do austríaco Hayek e do norteamericano Milton Friedman" (CHAUI, 2014, p.85). A proposta deste grupo atacava o chamado Estado-Providência com seus encargos sociais e com a função regulatória dos mercados, sua afirmativa baseava-se na ideia de livre comércio, redução de custos sociais, "abolição de investimentos estatais na produção, abolição do controle estatal sobre o fluxo financeiro, drástica legislação antigreve e vasto programa de privatização" (CHAUI, 2014, p.86). Este foi um modelo implementado a partir da década de oitenta em países como o Chile e que aparece, com força, no debate atual no Brasil de agora. Tal modelo político "foi responsável pela mudança da forma de acumulação de capital, hoje conhecida como acumulação flexivel" (CHAUI, 2014, p.87), uma vez que o pacote visava promover medidas para baixar a inflação (o que ocorreu) e o aumento do crescimento econômico, o que não ocorreu como promulgado uma vez que tal modelo econômico acabou gerando um efeito não previsto entre seus defensores, ou seja, acabou incentivando a especulação financeira em vez do investimento na produção. Reflexo que, nas economias do século XXI, acirra-se à medida que o dinheiro desloca-se para poucos e gigantes grupos financeiros os quais não geram investimentos físicos (não produzem mercadorias, bens), logo, não pagam (ou pagam muito pouco) impostos e este últimos, por não existirem ou estarem, 
Future-se: reflexões a partir de uma ideologia da competência e autoritarismo | Greice Martins Gomes

drasticamente, reduzidos não se revertem em investimentos sociais como saúde, transporte e claro: educação (DOWBOR, 2017) ${ }^{9}$.

Argumentamos, neste sentido, que programas como o Future-se surgem como a materialização de uma ideologia da competência aplicada à formulação e implementação de políticas públicas, no caso, voltadas ao campo educacional. A partir de seus princípios, fomentados a partir de um viés especificamente econômico, se produz uma universidade orientada para resultados e com a clara inclinação de se amarrar pesquisa ao mercado. Está no cerne do Future-se a proposta de financiamento privado nas pesquisas realizadas nas universidades federais, bem como está no centro disto a tendência de aceitação acrítica das pesquisas, atendendo as demandas mercadológicas, em que se perde de vista o papel público da investigação e a liberdade universitária para definir prioridades, conteúdos, formas e utilização das pesquisas. É a partir desta racionalidade que se torna clara declarações que atacam as áreas de pesquisas ligadas as humanidades (como sociologia e filosofia) ${ }^{10}$. Afinal, este tipo de produção (filosófica, sociológica) por suas particularidades - não apenas de crítica e reflexão social, política e econômicas - geram uma produção que não é algo que possa ser inserida imediatamente no mercado. Dizendo isto de outro modo, é possivvel inserir no mercado quase de imediato uma nova tecnologia, um novo remédio, um novo modelo de custos, uma inovação em engenharia, em produção, em transporte, em extração de minério, contudo, um novo conceito que pense o social a partir de uma reflexão inerente as condições de nossa à realidade, como, por exemplo, o conceito de Racismo Estrutural11 não é algo que estará à venda nem pronto para um 'consumo' imediato. Não obstante, o adentramento de uma ideologia da competência e seu viés mercadológico, administrativo-organizacional nas universidades públicas

\footnotetext{
9 Para mais detalhes sobre esta discussão indicamos: LADISLAU DOWBOR (SITE). A Era do Capital Improdutivo. Disponivel em: https://dowbor.org/principais-livros/. Acesso em: 1 dez. 2019.

10 Conforme matéria no Jornal Folha de são Paulo: Bolsonaro propõe reduzir verba para cursos de sociologia $e$ filosofia no país. https://www1.folha.uol.com.br/educacao/2019/04/bolsonaro-propoe-reduzir-verba-para-cursos-desociologia-e-filosofia-no-pais.shtml. Acesso em: 1 dez. 2019.

11 Para informações adicionais sobre este tema sugerimos: ALMEIDA, Silvio. O que é Racismo Estrutural? Belo Horizonte: Letramento, 2018.
} 
Future-se: reflexões a partir de uma ideologia da competência e autoritarismo | Greice Martins Gomes

subordina a pesquisa à velocidade e à descartabilidade próprias do mercado contribuindo, com isto, para o declínio do princípio político de responsabilidade social, inerente à ideia de universidade.

De acordo com Chauí (2014) ao empregar-se critérios que visam, entre outras coisas, a criação de uma homogeneidade (comum dentro de um modelo organizativo-administrativo) despoja-se a universidade pública de sua especificidade, isto é, a diversidade e a pluralidade de suas atividades determinadas pela natureza própria dos objetos de ensino e pesquisa. Insere-se no contexto da universidade racionalidades, finalidades $\mathrm{e}$ temporalidades específicas de uma lógica de mercado. O próprio conceito de "produtividade", inerente a ideia de Organização, quando trazido para dentro da universidade remete a um corpo docente que passa a ensinar (replicar?) a mesma coisa para o maior número de pessoas. Fomentando-se assim um "dar a conhecer que não possa pensar. Adquirir e reproduzir para não criar, consumir, em lugar de realizar o trabalho de reflexão" (CHAUI, 2014, p.75). Neste contexto, a educação passa a ser um negócio muito mais do que um processo de inclusão, avanço social, desenvolvimento nacional e legitima-se, perante a sociedade, a concepção do ensino e da escola como capital. Institui-se um sistema de poder em que a partir de uma ideologia da competência dentro do qual "administrar" significar impor - não importa qual realidade, situação ou objeto - um mesmo conjunto de princípios, preceitos e normas baseado em um formalismo vazio, de modo que "nessa perspectiva não há a menor diferença entre a Volkswagem, a Petrobras ou a universidade" (CHAUI, 2014, p.71).

\section{As diferentes faces de um autoritarismo à brasileira}

São dificuldades específicas que a sociedade brasileira nos coloca para pensarmos o social. Elas estão relacionadas tanto à ambiguidade como tratamos a vinculação público-privado, quanto às relações sociais baseadas em uma dualidade ontológica marcada pela ideia de um agente superior (aquele que manda) e um inferior (aquele que obedece). Desencadeia-se, com 
Future-se: reflexões a partir de uma ideologia da competência e autoritarismo | Greice Martins Gomes

isto, uma conjuntura em que o outro não é reconhecido enquanto sujeito, muito menos como sujeito de/com direitos, ao que se esvazia juntamente a ideia tanto de alteridade quanto sobre o que vem a ser um direito. A universidade pensada dentro de tal processo de significação é um lugar não para todos, no sentido democrático, mas para poucos, no sentido do mercado. É o agravamento de tal injunção que faz com que o produto final da universidade pública se torne um produto (de fato), vendido e negociado por (e para) aqueles com capacidades de pagar mais, melhor. Neste interim, o autoritarismo brasileiro, através de suas diversas faces, surge como um fator de relevância para compreensão dos programas atuais como o Futurese.

Iniciemos refletindo que no neoliberalismo, em essência, não se acredita em sociedade, acredita-se no individuo - em particular em um ideário de indivíduo hobbesiano, egoísta e competitivo por natureza - logo: o neoliberalismo não concebe uma sociedade, ele concebe um mercado. A ideologia que sustenta o regime neoliberal de acumulação é fundada a partir da constituição da sociedade enquanto grupo de indivíduos que podem ser analisados separadamente ${ }^{12}$. O foco no indivíduo sustenta a concepção de mercado orientada por agentes econômicos movidos por seu próprio interesse e, portanto, sem fim social. Ou, ainda, como coloca Marilena "o neoliberalismo é o encolhimento do espaço público dos direitos e o alargamento do espaço privado dos interesses de mercado" (CHAUI, 2014, p. 88). Razão pela qual politicas neoliberais tendem a não se importar com a ideia de democracia, uma vez que esta última pressupõe a ideia de sociedade. Isto posto, podemos considerar que existe um antônimo, ou seja, uma construção socialmente contrária, incompativel, antagônica à democracia, ela chama-se: autoritarismo (SCHWARCZ, 2019).

Enquanto a democracia, proveniente do Grego demokratia e que significa governo do povo, tem a ver com liberdade, igualdade e direito de expressão o autoritarismo se relaciona com o desrespeito as formas de

12 Proposição que pode ser resumida através da expressão "não existe sociedade; o que existe são indivíduos (frase de Margareth Thatcher ex-primeira ministra do Reino Unido de 1979 a 1990. 
Future-se: reflexões a partir de uma ideologia da competência e autoritarismo | Greice Martins Gomes

articulação social bem como tende a forçar o povo à obediência passiva e à despolitização. Por seu turno, "o autoritarismo brasileiro possui antigas e arraigadas raízes históricas, embora frequentemente mascaradas pela mitologia nacional" (SCHWARCZ, 2019, p.9). Entre os elementos de destaque estão a nossa história de mais de trezentos anos de escravidão, nosso racismo estrutural e práticas metamorfoseadas em nosso cotidiano envolvendo o personalismo e o mandonismo.

O mandonismo tem sua origem brasileira a partir de uma espécie de aristocracia meritória e não hereditária como a europeia, para a qual, a predisposição ao mando estava atrelada a uma alta concentração da riqueza e poder. E, "de fato, se tomarmos como exemplo o conjunto das famílias dos proprietários coloniais do Nordeste açucareiro, fica claro que poucos eram fidalgos portugueses" (SCHWARCZ, 2019, p.30) Segundo a autora, surgiu neste contexto um modelo de família que constituía o núcleo de um latifúndio rural em que os senhores de engenho educavam seus filhos (homens) para perpetuação de seu poder e as filhas (mulheres) eram pensadas como moeda para trocas e alianças. Formação familiar primordial que resultaria na constituição das elites brasileiras marcada, entre outras coisas, pela noção de poder, superioridade, autoridade (desprezo?) em relação ao restante da população e particularmente dirigida às classes menos privilegiadas economicamente. Argumentamos, quanto a isto, que nossos traços originais de mandonismo que sustentam a ideia de superior/inferior, são, em larga medida, responsáveis pela nossa recusa tácita de se fazer operar o princípio da igualdade. Em uma sociedade com dificuldades de lidar com a ideia de igualdade, investimentos estatais como em uma educação - pública, democrática e universal - tendem a ser vistos com dispêndio e não como investimento em prol do desenvolvimento, tanto econômico como social, de todo um país.

O patrimonialismo, por sua vez, vê uma fronteira tênue (ou quase inexistente) entre o público e privado. Ele se alastra e se transmuta temporalmente dos senhores de engenho, que como dito eram o próprio 
Future-se: reflexões a partir de uma ideologia da competência e autoritarismo | Greice Martins Gomes

Estado, até os dias atuais através da chamada bancada dos parentes que, segundo dados do DIAP (2018) aumentou, significantemente, em 2018. De acordo com SCHWARCZ (2019) o patrimonialismo de hoje se mostra no controle/domínio da coisa pública por (e para) interesses privados. Possivelmente um dos mais ilustrativos exemplos deste tipo de articulação pode ser retirado da votação do impeachment de Dilma Rousseff, em 31 de agosto de 2016. Na ocasião, a maioria dos parlamentares realizaram disputas discursivas onde foi possivel observar manifestações com explícitas referências ao nosso passado patrimonialista. Pimenta (2019), através de um trabalho de análise das falas e discursos proferidos em tal sessão, nos revela que os deputados que votaram pela destituição da então presidenta Dilma foram os que mais trouxeram referências à família, mas note-se: às suas famílias. As referências à família revelam sobre uma perspectiva privada, individual e pessoal, haja vista que as menções giravam em torno de seus filhos, não os filhos dos outros deputados, sobre os seus netos, não os netos de quaisquer outros sujeitos, quanto as suas esposas, não a nenhuma outra esposa (ou marido) de outrem. São componentes que expõe sobre uma concepção de sociedade que mantém sua ênfase privada (a vida pessoal de cada parlamentar) na esfera pública (mesmo tratando-se de uma votação oficial sobre um assunto de Estado). O que presenciamos naquele momento traz elementos simbólicos de expressiva pertinência sobre usos passados sendo manobrados e (re)confirmados ainda nos dias de hoje. Ademais, o patrimonialismo a partir de um núcleo familiar marcado pelo poder e pelo mando, baseado no clientelismo, no favor e na dependência quando não recusa, atrapalha o trabalho dos conflitos e das contradições. Neste cenário, pensamentos críticos e reflexivos, como os incentivados dentro da universidade, tendem a ser vistos com olhares depreciadores, levando ao descrédito, desprestigio e a deslegitimidade da própria instituição universidade como é perceptível nas falas de governantes em tempos de Future-se.

Já na base de nossa violência social, aplicada ainda hoje, principalmente, às populações pretas e pardas (IBGE, 2018), está a nossa 
Future-se: reflexões a partir de uma ideologia da competência e autoritarismo | Greice Martins Gomes

história escravocrata. É ela que, tendo como marca original a violência contra milhões de negros e negras que foram retirados de suas terras e trazidos como escravos para aqui trabalhar, dá sustentação a rudimentos que nos são particulares (SCHWARCZ, 2019). Entre eles a definição de estereótipos e preconceitos, tais como nossa incontestável desvalorização do trabalho braçal, bem como a noção de exclusão do 'outro' que tem como referência uma ideologia iniciada pela diferenciação da cor da pele. Estas formas de exclusão, conforme acrescenta a autora, são reconstruídas no presente em nossa definição tida como "válida" quanto ao nosso modelo de família, no machismo, na misoginia e em nossa forma hierarquizada de mando. Hoje, escravidão e racismo (re)surgem através de marcadores sociais como raça e gênero em um contexto ainda altamente segmentário e discriminatório e inegavelmente presente nos indices de morte, encarceramento, de moradia em periferias, e claro, de acesso e formação a uma educação, em especial de nível superior (IBGE, 2019). O autoritarismo pensado a partir do elemento escravidão dá origem a formação de uma sociedade cindida na qual a educação superior foi, historicamente - e até pouco tempo atrás - um privilégio das classes mais ricas. Com a entrada substancial de camadas mais pobres ao ensino superior (ANDIFES, 2018), não é de se espantar que políticas/tentativas de reversão deste cenário ganhem força no cenário atual, apoiadas em um engendramento histórico baseado na ideia de separação, de segmentação social, violência e preconceito.

Se o autoritarismo brasileiro tende a potencializar sua forma de expressão em momentos extremos de decréscimo de direitos e de cidadania, como no periodo de ditadura militar, como mencionamos, hoje, o autoritarismo não precisa de um governo de exceção para atingir sua expressão máxima. Na atualidade, o que vemos remete à uma realidade em que governos eleitos trabalham com uma produção intensa de medidas de exceção a partir da estrutura democrática. Projetos como o Future-se evidenciam um vício autoritário - fruto de estrutura social totalitária e, 
Future-se: reflexões a partir de uma ideologia da competência e autoritarismo | Greice Martins Gomes

portanto, violenta, hierárquica, vertical, oligárquica, conservadora, racista e violenta - constitutivo do tecido social brasileiro que se apropria da ideologia da competência para promover reformas neoliberais no campo da educação.

\section{Considerações Finais}

Assumindo que o patrimonialismo se mostra no controle/domínio da coisa pública por (e para) interesses privados, ele estaria, portanto, presente na proposta basilar que sustenta o Future-se, qual seja: a de transformar o que seria um direito (o acesso ao ensino superior) em um serviço, vendido e negociado no mercado por e para aqueles que podem pagar por ele. $\mathrm{O}$ mandonismo que marca as elites brasileiras através da ideia de poder, superioridade, autoridade (e desprezo?) em relação ao restante da população, se mostra no Future-se através da noção de que a universidade não deve ser de acesso a todos e sim somente aos "melhores"13 o que em um contexto brasileiro de exclusão e injustiça social aliado a ferinos índices de distribuição de renda não deixa dúvida sobre quem são, e de onde vem, aqueles que seriam considerados os "melhores". Nossa herança escravocrata e racista (re)surge através de marcadores sociais, os quais revelam sobre um contexto social ainda altamente segmentário e discriminatório presente, por exemplo, em nossos baixos índices de formação universitária pela massa da população brasileira (IBGE, 2018).

Apesar da educação ser, possivelmente, a forma mais elementar para elaborações sociais que busquem alternativas outras, quanto ao nosso passado (e presente) marcados por um autoritarismo constitutivo - ou, ainda, como coloca Ribeiro (1995), é a educação aquilo que representará um papel relevante na luta pela edificação de novos tipos de sociedades mais justas e mais igualitárias ${ }^{14}$ - o projeto Future-se posta-se em uma direção contraria a tal proposição. De modo que o autoritarismo a nós atinente, traz

\footnotetext{
13 Conforme matéria no Jornal GGN: Brasil não tem espaço para todos, só para os melhores, diz Weintraub a crianças. Disponivel em: https://jornalggn.com.br/noticia/brasil-nao-tem-espaco-paratodos-so-para-os-melhores-diz-weintraub-a-criancas/. Acesso em: $1^{\circ}$ dez. 2019.

14 Ao que nos alerta Ribeiro (1995): não se trata de qualquer educação e sim aquela que nos que ensine a pensar criticamente e não apenas a reproduzir.
} 
Future-se: reflexões a partir de uma ideologia da competência e autoritarismo | Greice Martins Gomes

elementos relevantes para discutirmos o agravamento de políticas neoliberais que fazem com que a universidade se distancie da sociedade tanto como princípio como referência valorativa e dê lugar a uma visão organizacional, administrativa, individualista, anticoletivista e competitiva sobre o ser e estar social. Tais conjunções históricas, atreladas a uma ideologia da competência, resultam no encolhimento do espaço público e na ampliação do espaço privado através da transmutação de direitos em privilégios para benefício a uma "elite", bem como na ampliação das carências e aniquilamento, ainda maior, da cidadania em relação à classe popular (CHAUI, 2014).

Contudo é importante salientarmos: a história não explica totalmente nosso presente e nem serve como "bula de remédio" (SCHWARCZ, 2019). Logo, entender nossos meandros primordiais e como se articulam com questões de nosso tempo, surge como um instrumento importante no sentido de nos dar pistas, de nos fazer pensar; oportuniza que se diminuam certas opacidades do olhar, trazendo nitidez contra o que devemos lutar. 
Future-se: reflexões a partir de uma ideologia da competência e autoritarismo | Greice Martins Gomes

\section{Referências}

ADUSP (Associação dos docentes da Universidade de São Paulo). Para o MEC, "Future-se" vai transformar a educação brasileira em "produto de exportação".

Disponivel

em: <https://www.adusp.org.br/index.php/defesauniv/3380-para-o-mec-futurese-vai-transformar-a-educacao-brasileira-em-produto-de-exportacao > Acesso em: 1 dez. 2019.

ANDIFES. Relatório do Perfil Socioeconômico e Cultural dos Estudantes de Graduação das Universidades Federais Brasileiras. Fórum Nacional de Pró-Reitores de Assuntos Comunitários e Estudantis (FONAPRACE). Brasília, 2018

CHAUI, M. A ideologia da competência. São Paulo, Fundação Perseu Abramo/ Autêntica, 2014.

CHAUÍ, Marilena. Aula de abertura do ano letivo da ENSP, Museu da Vida/Fiocruz (São Paulo), mar. 2015. Disponivel em: $<$ https://www.youtube.com/watch?v=TNQg95QIvsQ\&t=1065s> Acesso em 30 de nov. de 2019.

CHAUÍ, Marilena. Contra a universidade operacional e a servidão voluntária. Palestra de abertura do Congresso da Universidade Federal da Bahia. 14 de julho de 2016.2 Disponivel em:<https:/ / www.ufba.br/noticias/conhe\%C3\%A7a-palestra-contrauniversidade-operacional-e-servid\%C3\%A3ovolunt\%C3\%A1ria>. Acesso em: 15 jun. 2016.

CHAUÍ, Marilena. Cultura e democracia. 4. ed. São Paulo: Cortez, 2017.

DIAP - DEPARTAMENTO INTERSINDICAL DE ASSESSORIA PARLAMENTAR. Eleições 2018: bancada de parentes cresce no Congresso Nacional. Disponivel em: https: / / www.diap.org.br/index.php/noticias/noticias/28527-eleicoes-2018bancada-de-parentes-cresce-na-camara-dos-deputados. Acesso em: 1 dez. 2019.

DOWBOR, Ladislau A era do capital improdutivo: Por que oito famílias têm mais riqueza do que a metade da população do mundo? São Paulo: Autonomia Literária, 2017.

DURHAM, E. O ensino superior no Brasil: público e privado. São Paulo: USP, 2003.

IBGE. Instituto Brasileiro de Geografia e Estatística. (2018b) Sintese de indicadores sociais: uma análise das condições de vida da população brasileira. 2018. Disponivel em 
Future-se: reflexões a partir de uma ideologia da competência e autoritarismo | Greice Martins Gomes

<https://biblioteca.ibge.gov.br/visualizacao/livros/liv101629.pdf > Acesso em: 12 nov. 2019.

LEFORT, Claude. Esboço de uma gênese da ideologia nas sociedades modernas. Estudos, São Paulo: CEBRAP. n. 10, 1974.

MEC (Ministério da Educação). FUTURE-SE. Disponível em: http:/ / portal.mec.gov.br/busca-geral/12-noticias/acoes-programas-eprojetos-637152388/78351-perguntas-e-respostas-do-future-se-programade-autonomia-financeira-do-ensino-superior. Acesso em: 1 dez. 2019.

NEXO. Qual o plano do MEC para as federais captarem recursos privados. Disponivel em: <https://www.nexojornal.com.br/expresso/2019/07/17/Qual-o-plano-doMEC-para-as-federais-captarem-recursos-privados $>$. Acesso em: 1 dez. 2019.

PIMENTA, João Paulo. Direita sequestrou noção de futuro $(01 \mathrm{~h} 35 \mathrm{~m})$. Disponivel em: <https://www.youtube.com/watch?v=6qq6q188Vgs\&t=4419s $>$ Acesso em: 26 de nov. 2019.

RAMOS, A. G. A nova ciência das organizações. Rio de Janeiro: Editora da Fundação Getúlio Vargas, 1989.

RIBEIRO, Darcy. O Destino Nacional. In: RIBEIRO, Darcy. O Povo Brasileiro. São Paulo: Companhia das Letras, 1995.

ROCHA, André. Apresentação. In: CHAUI, M. A ideologia da competência. São Paulo, Fundação Perseu Abramo/ Autêntica, 2014, p. 7-16.

SCHWARCZ, Lilia. Sobre o Autoritarismo Brasileiro. São Paulo: Companhia das Letras, 2019. 